
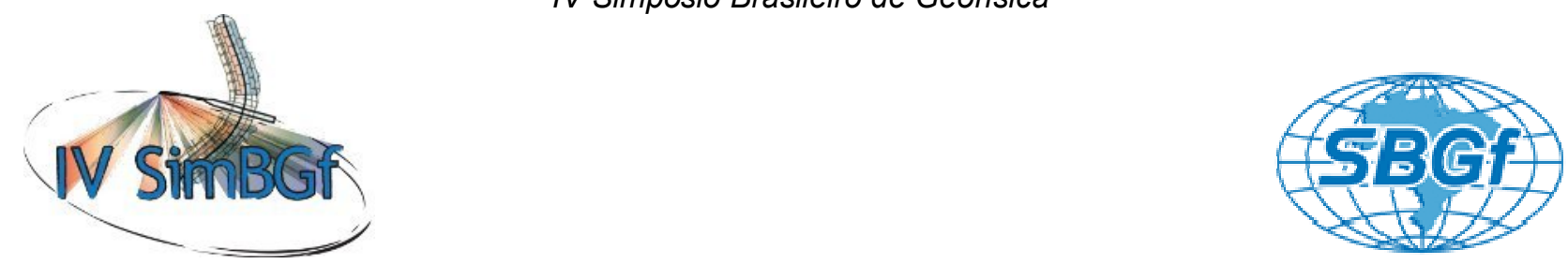

\title{
Utilização do GPR para detectar uma estrutura enterrada em uma companhia siderúrgica
}

José Tavares Araruna Júnior, Patrício José Moreira Pires. Pontifícia Universidade Católica do Rio de Janeiro. Jayme de Paula Filho. Soilution Hidrogeologia e Consultoria Ambiental Ltda.

Copyright 2010, SBGf - Sociedade Brasileira de Geofísica

Este texto foi preparado para a apresentação no IV Simpósio Brasileiro de Geofísica, Brasilia, 14 a 17 de novembro de 2010. Seu conteúdo foi revisado pelo Comitê Técnico do IV SimBGf, mas não necessariamente representa a opinião da SBGf ou de seus associados. É proibida a reprodução total ou parcial deste material para propósitos comerciais sem prévia autorização da SBGf.

\section{Resumo}

O presente trabalho apresenta a aplicação do radar de penetração (gpr) na identificação da estratigrafia local e de possíveis objetos enterrados em uma área de uma companhia siderúrgica. O levantamento tinha a finalidade de adquirir um conhecimento prévio da área sem a necessidade de grandes escavações. $A$ área no passado foi utilizada com pátio depósito de minério $e$ possivelmente de estoque de resíduo e tambores. Atualmente ela é utilizada como estacionamento e será empregada para a construção de uma nova fábrica de oxigênio para a companhia siderúrgica. $O$ levantamento gpr identificou no local uma laje retangular com aproximadamente $33 \mathrm{~m} \times 50 \mathrm{~m}$ a uma profundidade de cerca de 3 metros. O levantamento ainda detectou no local a posição do nível d'água e diversas feições adjacentes a laje que podem ser associadas a aterros de distintas origens e diferentes tipos de solos.

\section{Introdução}

O aumento da demanda por insumos em decorrência do momento favorável que passa a economia brasileira acarreta na otimização de espaços em unidades industriais. Áreas que antes eram ocupadas por bosques ou estacionamentos agora estão virando canteiros de obras para implantação de novas plantas.

Em geral, estas áreas já possuem uma infra-estrutura instalada (e.g., sistemas de distribuição de água, sistemas de coleta de efluentes, cabos de telefonia, de energia e de fibra ótica) que necessitam ser cadastrada antes do início das operações de investigação geotécnica. Adicionalmente, algumas delas podem ainda conter estruturas enterradas fruto de uma utilização pretérita.

Há um consenso no meio técnico que as investigações não destrutivas, que empregam métodos geofísicos, podem atuar de uma maneira eficaz no levantamento destas informações (Rodrigues \& Porsani, 2006). Existe uma série de casos relatados na literatura onde a aplicação da geofísica acarretou na otimização do programa de investigação geotécnica e na redução de custos (e.g., Araruna Jr. et al., 2002, Souza et al., 2006).
No entanto, a aplicação de métodos geofísicos em áreas urbanas e plantas industriais ainda representa um desafio devido a grande quantidade de interferências presentes em sub-superfície (Araruna Jr. et al., 2007).

O presente trabalho apresenta e discute o programa experimental que envolveu sondagens geofísicas com o radar de penetração (gpr) conduzido em uma companhia siderúrgica. As sondagens pretenderam cadastrar a infraestrutura existente e detectar possíveis elementos enterrados em um pátio de estacionamento que dará lugar a uma nova fábrica de oxigênio.

\section{Metodologia Empregada}

O levantamento geofísico foi executado empregando um radar de penetração (gpr) da marca MalaGeoscience, modelo Ramac. O equipamento consiste de uma unidade de aquisição e controle instalada em uma mochila, ou em carrinho, onde os sinais das ondas eletromagnéticas emitidos e recebidos são transferidos para um monitor que permite a visualização dos sinais eletromagnéticos e o seu armazenamento em meio digital.

O posicionamento das antenas foi realizado através de um odômetro que transmite os sinais eletromagnéticos a unidade de aquisição e controle, e por um sistema de posicionamento global geodésico da Marca Ashtech, modelo Promark II, que permite, através do pacote computacional GPS Mapper ${ }^{\circledR}$, visualizar o posicionamento das sondagens geofísicas no pacote computacional Google Earth ${ }^{\circledR}$.

Os perfis foram adquiridos através da utilização de antenas RTA's (Rough Terrain Antennas) de 50 e $100 \mathrm{MHz}$ e através de uma antena blindada de $250 \mathrm{MHz}$. A freqüência central de cada antena foi escolhida por propiciar uma boa penetração do sinal até a profundidade de interesse.

A aquisição de dados gpr foi realizada utilizando-se o programa GroundVision ${ }^{\circledR}$ e, para os perfis executados com a antena de $250 \mathrm{MHz}$, foram adotados os seguintes parâmetros:

- $\quad$ número de amostras por scan (traço) - 1024;

- número de stacks (empilhamento) - automático;

- $\quad$ range (janela temporal) - 273,1ns;

- $\quad$ intervalo entre scans (traços) - 0,019m;

- sem ganho; 
- nenhuma filtragem.

Para os perfis executados com a antena RTA de $100 \mathrm{MHz}$, foram adotados os seguintes parâmetros:

- número de amostras por scan (traço) - 608;

- $\quad$ número de stacks (empilhamento) - 16;

- $\quad$ range (janela temporal) - 492,8ns;

- $\quad$ intervalo entre scans (traços) - 0,099m;

- $\quad$ sem ganho;

- nenhuma filtragem.

Já para os perfis executados com a antena RTA de $50 \mathrm{MHz}$, foram adotados os seguintes parâmetros:

- número de amostras por scan (traço) - 576;

- $\quad$ número de stacks (empilhamento) - 16;

- $\quad$ range (janela temporal) - 972,8ns;

- $\quad$ intervalo entre scans (traços) - 0,099m;

- $\quad$ sem ganho;

- nenhuma filtragem.

Os dados adquiridos foram processados utilizando-se o programa RadExplorer ${ }^{\circledR}$. Todos os radargramas obtidos foram processados utilizando-se os mesmos recursos de processamento. Primeiramente, corrigiu-se o atraso da onda direta para a posição zero e, em seguida, os dados foram filtrados com um filtro vertical, IIR filter, para delimitar a faixa de freqüência atingível pela antena utilizada. Uma função de ganho do tipo automática (AGC/SEC) em 10 pontos foi aplicada. Ainda, para uma melhor visualização dos dados, utilizou-se o recurso de ajustar a escala horizontal, skipping, o qual permite especificar o número de scans (traços) a mostrar. Para conversão da escala vertical em tempo (ns) em profundidade $(\mathrm{m})$, foi adotado o valor 9 para a constante dielétrica do material de fundação.

\section{Apresentação e Discussão dos Resultados}

A campanha foi realizada em 30 seções totalizando $1081 \mathrm{~m}$ de levantamento gpr. Foram levantados 363m com a antena blindada de $250 \mathrm{MHz}, 549 \mathrm{~m}$ com a antena RTA de $100 \mathrm{MHz}$ e $169 \mathrm{~m}$ com a antena RTA de $50 \mathrm{MHz}$.

A locação das seções foi realizada pelo sistema gps geodésico no modo de navegação. Não foi possíve empregar o modo geodésico, e obter uma maior exatidão na aquisição dos sinais dos satélites, devido ao sombreamento existente na área decorrente da presença de edificações próximas ao local do levantamento gpr aliada a existência de superfície metálicas. Assim, como pode ser notado na Figura 1, o posicionamento das seções levantadas ficou deslocado na imagem de satélite.

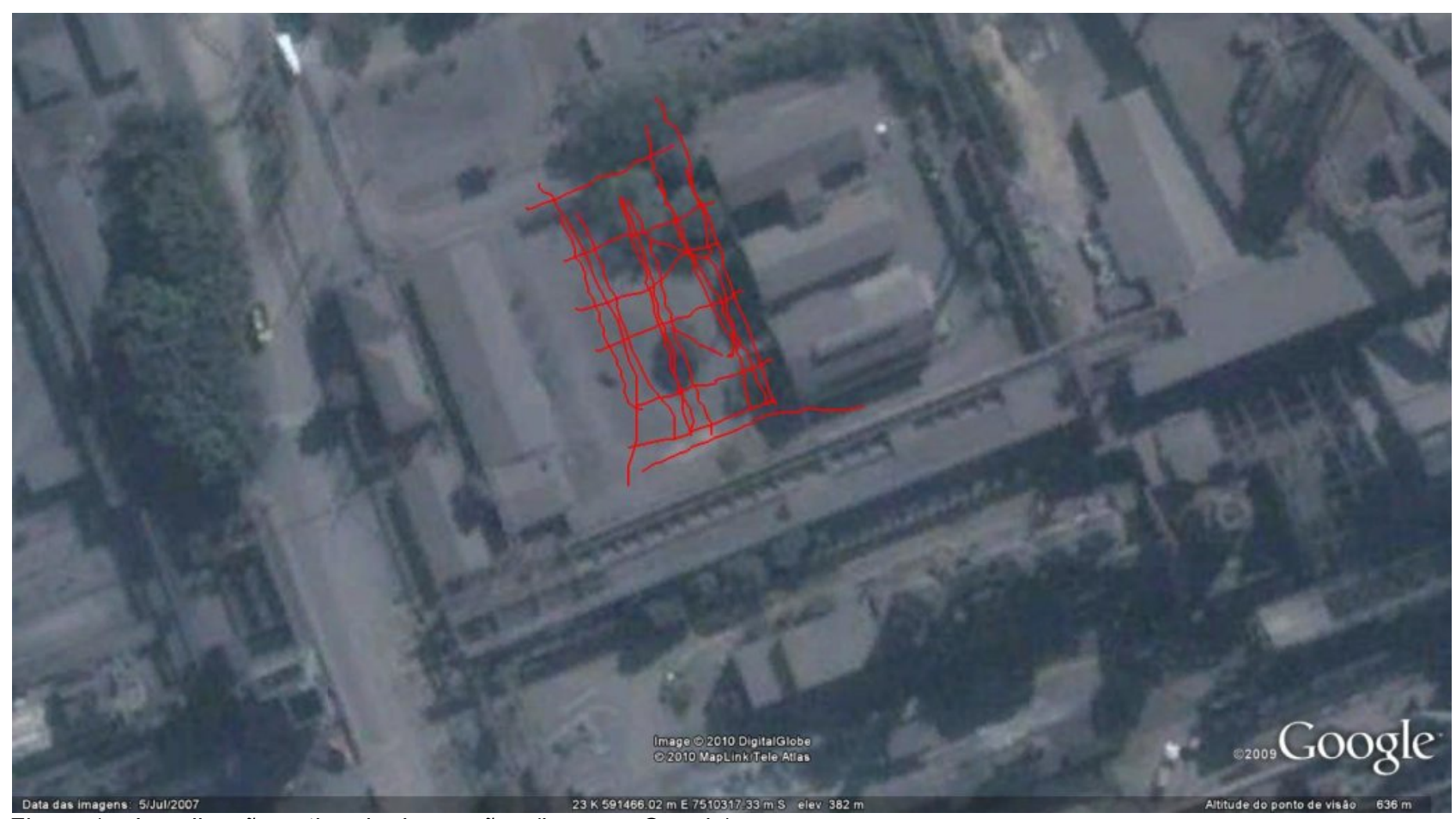

Figura 1 - Localização estimada das seções (imagem Google) 
A antena de $250 \mathrm{MHz}$ foi empregada para determinação das feições mais próximas à superfície (i.e., até $4 \mathrm{~m}$ de profundidade). O radargrama típico processado, visto na Figura 2, permitiu identificar o nível d'água a uma profundidade de cerca de $1,8 \mathrm{~m}$ da superfície do terreno.
As investigações também permitiram detectar interferências horizontais a cerca de $3,2 \mathrm{~m}$ da superfície do terreno. Estas interferências podem estar associada a presença de uma laje com cerca de $33 \mathrm{~m}$ de largura.

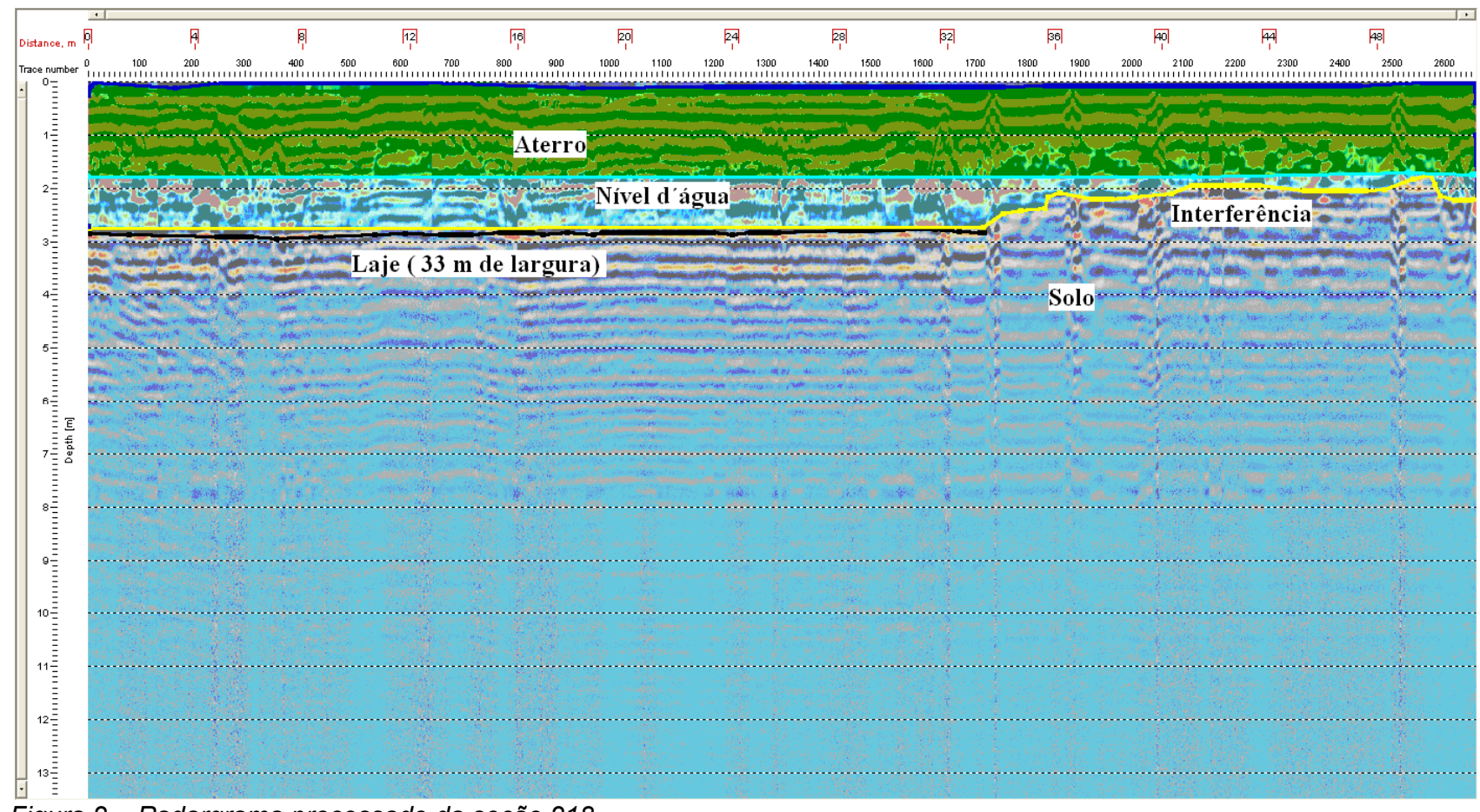

Figura 2 - Radargrama processado da seção 218

A antena de $100 \mathrm{MHz}$ foi empregada para determinar as feições em profundidades superiores. O radargrama típico processado, visto na Figura 3, também identificou interferências horizontais no sentido ortogonal àquelas identificadas na Figura 2, corroborando na existência de uma laje de concreto com cerca de $30 \mathrm{~m} \times 50 \mathrm{~m}$ conforme está indicado na Figura 4. Os resultados das seções gpr executadas com esta antena também confirmaram a posição do nível d'água determinado com a antena blindada de $250 \mathrm{MHz}$.

Em relação à estatigrafia do terreno foi possível distinguir a partir dos dados dos levantamentos com as antenas de $100 \mathrm{MHz}$ e $50 \mathrm{MHz}$ três materiais distintos. Acredita-se na existência de uma camada de aterro sobrejacente a laje de concreto. A profundidade desta camada é variada, se estendo entre 2 a $3 \mathrm{~m}$ de espessura. Abaixo da laje de concreto foram detectados dois tipos de materiais distintos, como ilustram as Figuras 3 e 5, que apresentam os resultados de duas seções ortogonais.

Nas camadas destes materiais não foram detectados feições indicativas de blocos ou matacões. Também não foram observados objetos enterrados, tais como tambores, nem indicativos de resíduos de natureza orgânica. 


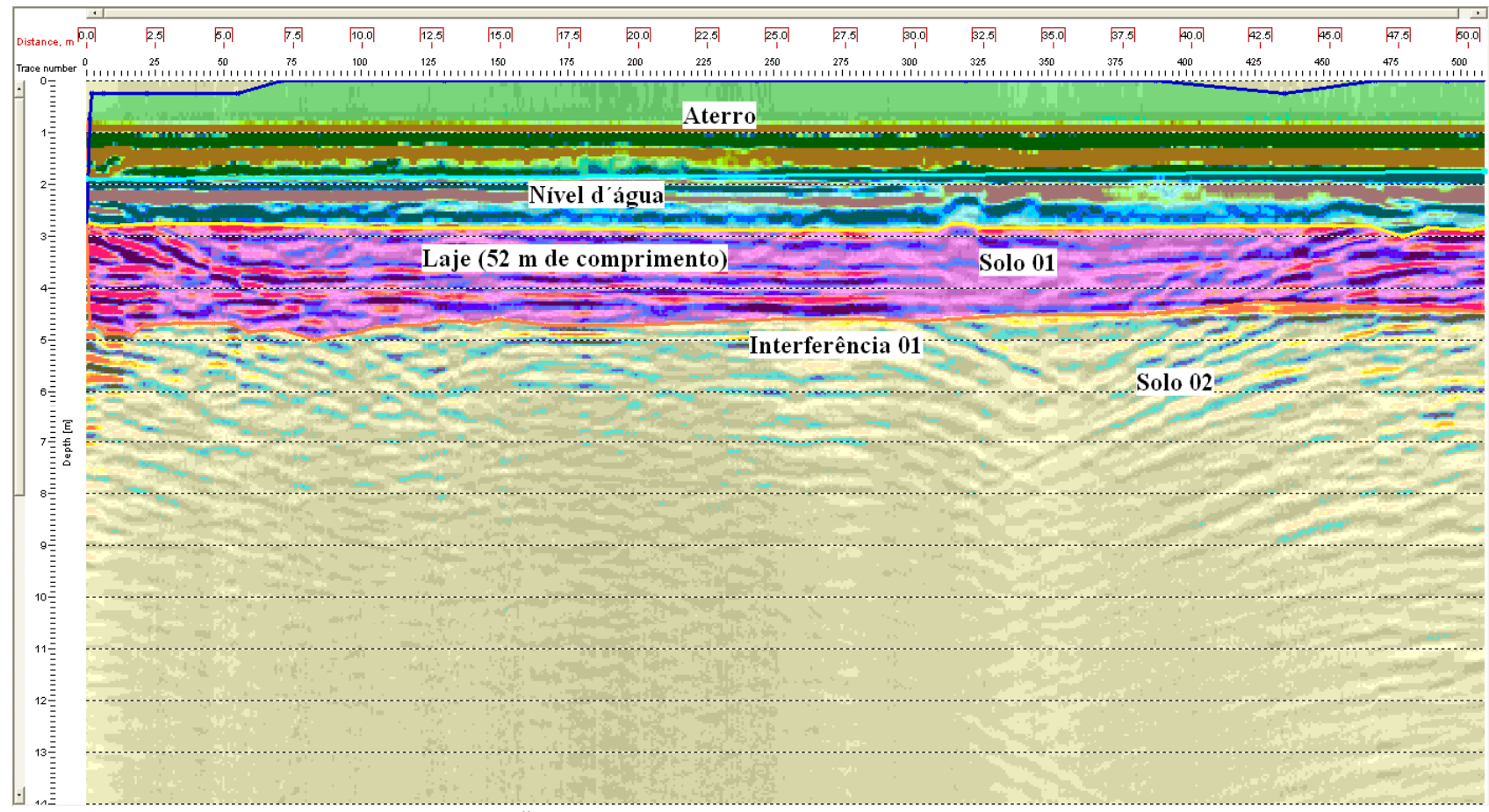

Figura 3 - Radargrama processado da seção 222

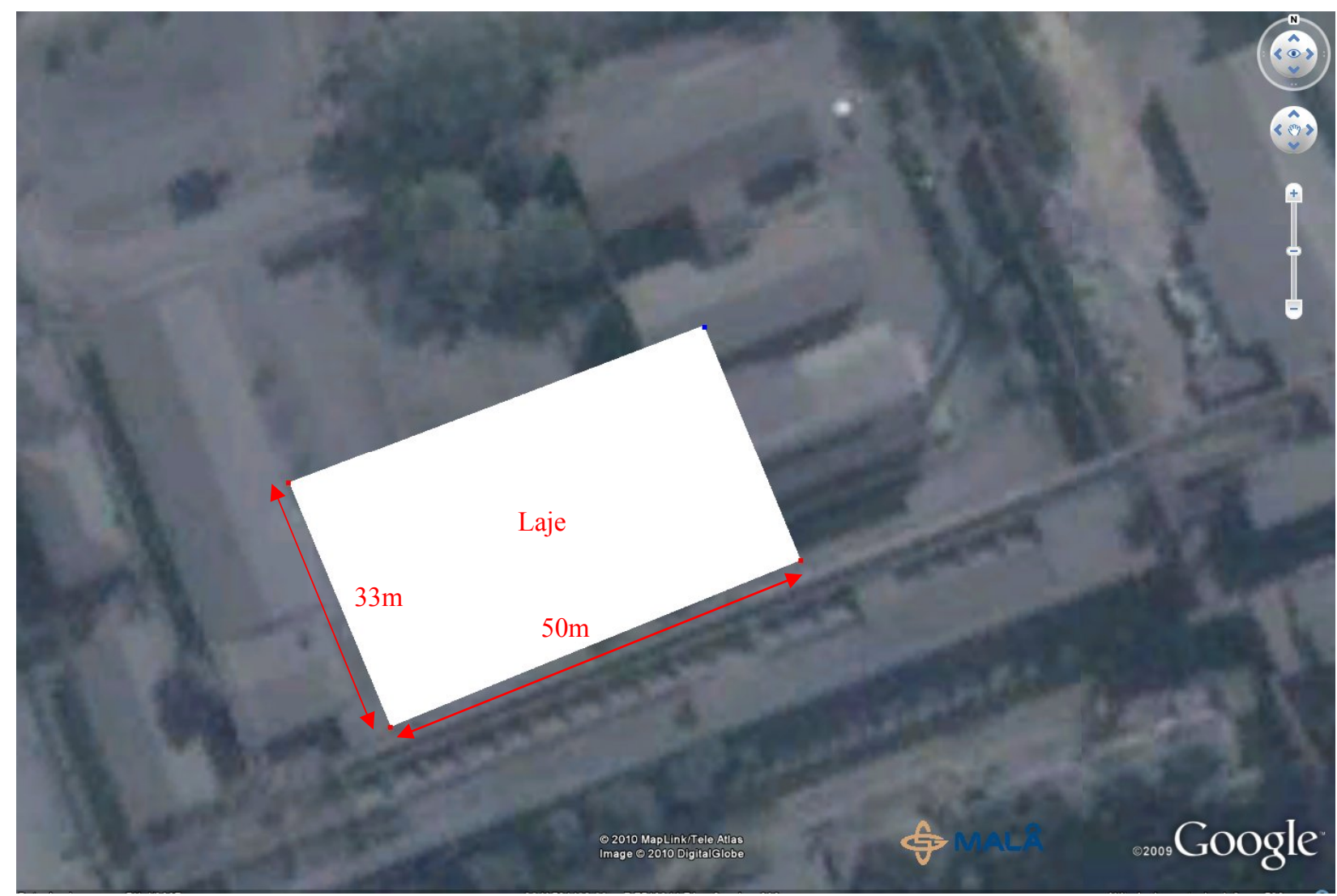

Figura 4 - Possível localização da laje de concreto 


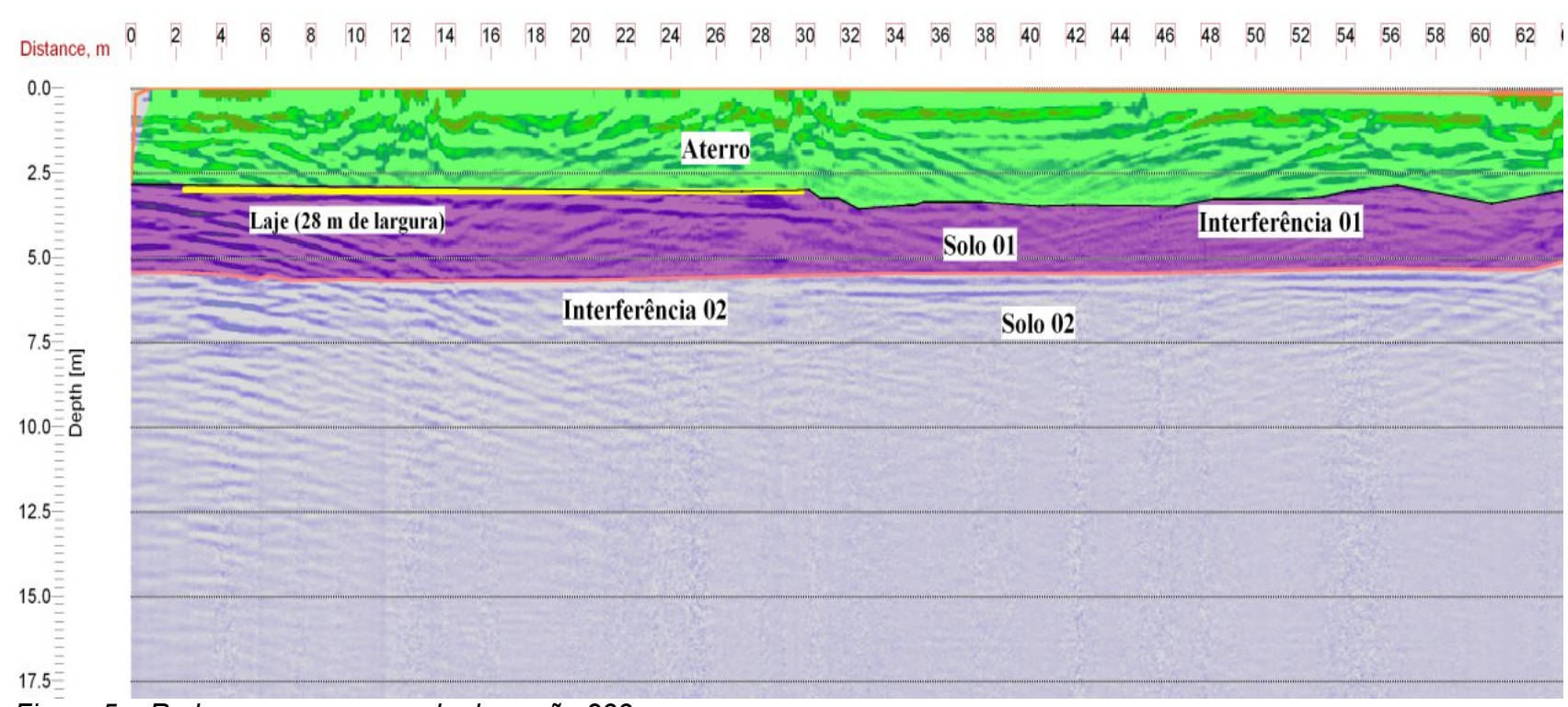

Figura 5 - Radargrama processado da seção 233

\section{Considerações Finais}

O levantamento gpr executado no local onde será construída a nova fábrica de oxigênio na companhia siderúrgica permitiu identificar anomalias típicas de estruturas enterradas e feições geológicas.

Acredita-se que a interferência horizontal detectada a cerca de $3,2 \mathrm{~m}$ de profundidade e que se estende por uma área de cerca de $30 \mathrm{~m} \times 50 \mathrm{~m}$ seja proveniente de uma laje de concreto. Informações colhidas junto a funcionários da companhia siderúrgica indicaram que a laje de concreto possa ser o piso de um antigo depósito de minérios localizado no local.

Em relação à estatigrafia do terreno, o levantamento gpr executado permitiu localizar o nível d'água e a presença de três materiais distintos. O levantamento não permitiu identificar feições típicas de blocos ou matacões nas camadas dos materiais subjacentes a laje. Também não se observou feições indicativas de objetos enterrados (e.g., tambores) e nem indicativos da presença de resíduos de natureza orgânica.

\section{Referências}

Araruna Jr. J.T., Nunes, C.M.O., Costa, A. e Vargas Jr, E.A. (2002). O emprego do radar de penetração (gpr) na detecção de elementos de fundação. Anais do XII
Congresso Brasileiro de Mecânica dos Solos e Engenharia Geotécnica, São Paulo, pp. 135-146.

Araruna Jr.,J.T., Pires, P.J.M., Pilotto, D.L. e Amaral, C.P. (2007). Considerações acerca da empregabilidade do radar de penetração (gpr) na detecção de elementos enterrados em áreas urbanas. Anais do VII Congresso Brasileiro de Geotecnia Ambiental - REGEO2007.

Iyomasa, W.S.; Galli, V.L,; Blanco, R.G \& Campos, G.C. (2006). O uso do radar de penetração no solo para localização de dutos em áreas urbanas: potencialidades e limitações. Revista Solos e Rochas, vol. 29, número 2, pp. 177-188.

Davis, J.L. \& Annan,A.P. (1989). Gound penetrating radar for high resolution mapping of soil and rock statigraphy. Geophysical Prospecting, vol. 37, pp. 531-551.

Rodrigues, S.I. e Porsani, J.L. (2006). Utilização do gpr para caracterizar tambores plásticos enterrados no sítio controlado de geofísico rasa do IAG/USP. Revista Brasileira de Geofísica, vol. 24, número 2, pp. 157-168.

Souza, M.M., Araruna Jr., J.T., Antunes, F.S. e Nunes, C.M.O. (2006). O uso do gpr para detecção de vazamentos de água. Estudo de caso: Parque Gráfico do Jornal O Globo - RJ. Anais do XIV Congresso Brasileiro de Águas Subterrâneas, pp. 1-15. 